\title{
주요국 가계금융
}

Micro DB 구축 동향

고제헌

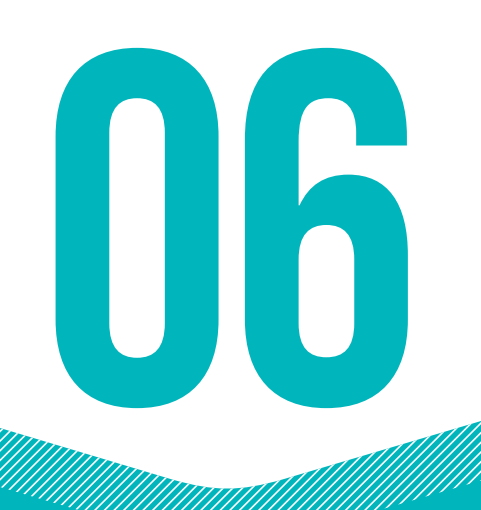

CONTENTS

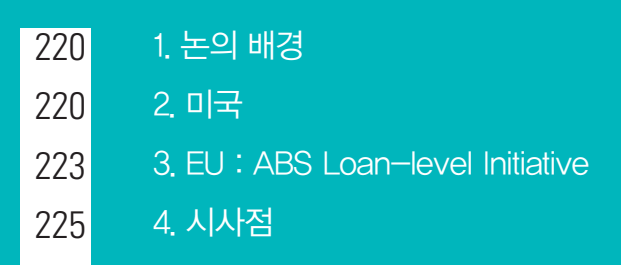


서브프라임 모기지 사태 이후 Micro $\mathrm{DB}$ 구축 필요성이 강조되며 미국 및 $\mathrm{EU}$ 국가들 에서 공적기관 주도하에 다각도로 가계부채 $\mathrm{DB}$ 구축 및 개선이 이루어지고 있음. 이들 사례를 통하여 국가 전체를 대표하는 가계부채 $\mathrm{DB}$ 를 성공적으로 구성하고 활용하기 위해서는 금융정보의 특수성에 기인한 많은 논의와 가계부채 통계의 특성에 대한 심도 깊은 연구가 전제되어야 함을 확인함.

\section{1. 논의 배경}

- 서브프라임 모기지 사태 이후 금융 시장 안정성 모니터링 및 정책적 판 단의 기초로서 Micro 통계의 중요성이 부각되고 있음.

$\triangleright$ 미국의 경우 공적기관을 중심으로 마이크로 가계부채 $\mathrm{DB}$ 를 보완 및 새로이 구축하고 있음

$\triangleright \mathrm{EU}$ 의 경우 $\mathrm{ECB}$ 중심으로 유동화된 대출에 한하여 각 금융기관들이 제출한 표준화된 템플릿을 제공하고 데이터를 수집하고 있음.

- 미국과 EU의 Micro DB 구축 방향 공통점은 중장기적인 로드맵 하에 충 분한 인력과 재원을 투입하여 점진적으로 진행되고 있다는 것임.

$\triangleright$ 예를 들어, 미국 The National Mortgage Database project의 경우 2012년 프로젝트가 시작되어, 현재 단계별로 DB 구축 중에 있음.

$\triangleright$ 또한, 수집 목적에 따라 기존 제도를 개편하고, 신규 $\mathrm{DB}$ 를 구축하며 모기지 시장에 대한 이해를 심화하기 위해 다양한 시도 중임.

\section{2. 미국}

1) $\operatorname{HMDA}($ Home Mortgage Disclosure Act) DB

- 금융소비자 보호를 위하여 금융기관들의 대출 행태 파악 목적으로 1975 년부터 수집을 시작함.

$\triangleright$ Regulation C에 의거 일정 요건을 갖춘 도심지역(metropolitan areas)에 지점을 갖고 있는 금융기관들에게 모기지 대출 활동 관련 정 보를 보고토록 요구함.
- FRB가 Regulation C 작성기관이었으나, 2011년 7월을 기점으로 소비자금융보 호국(CFPB)으로 이관됨.

- '16년 기준 6,913 개 금융기관이 대출실적을 신고하였으며, 대출정보는 1,430 만 건에 달함.

$\triangleright$ 주요 수집 정보는 지역 주택 수요 적절 대응 여부, 공공부문과 민간 부문 투자 적절 배분 여부, 약탈적 대출행위 및 공정 법에 기반을 둔 대출 여부 등의 판단 근거가 되는 정보 중심으로 구축되었음.

- 대출신청 일자, 대출유형, 주택유형, 대출목적, 점유형태, 대출규모, 대출시 사 전승인 여부, 대출거부 사유, 대출심사 결과, 대출시작일, 대출가격, 주택위치, 차주 인종 및 성별, 소득 등

가장 대표적인 공적 모기지 $\mathrm{DB}$ 이지만, 차입자 및 대출 상환에 대한 구 체적인 정보 부족으로 2018년 이후 보다 구체적으로 정보들을 추가 수 집할 예정임.

$\triangleright$ 대출시행 이후 9 21개월 시점 대출 정보만 취급하고 있음.

$\triangleright 2012$ 년 이후 금융기관 자산 규모의 기준치를 높이는 등 조사 대상 금 융기관 범위를 좁히고 있음.

$\triangleright$ 2018년부터 차입자 및 대출신청자의 연령, 신용점수, 자산가격, 대출 수수료, 조기상환수수료, 이자율, 대출 및 대출기관 식별 정보 등을 제공하도록 함.

[그림 6-1] 미국 대출목적에 따른 모기지 건수
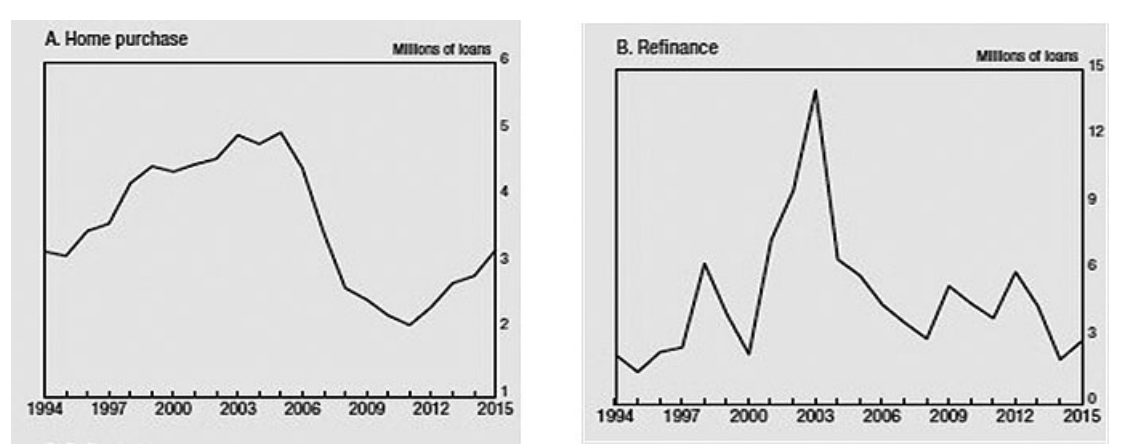

※ 자료 : Federal Reserve Bulletin November 2016, vol.102 № 6 
2) FRBNY CCP(Consumer Credit Panel)

- 2010년 뉴욕 연방청은 Equifax 신용정보데이터를 활용하여 가구 중심의 패널데이터를 구축

$\triangleright$ 사회보장번호와 신용기록이 있는 미국 거주자들 중 $5 \%$ 를 임의 추출하 여 표본 구축한 불균형 패널(unbalanced panel)로, 차주 중심의 $\mathrm{DB}$ 를 주소지에 기반하여 가구로 추정함

- 분기 미국 인구 통계에 기반을 두어 중첩세대모형(overlapping generation framework)을 적용하여 인구 통계상 신용거래 비율과 표본의 신용거래 비율 이 동일하도록 청년층과 이민자들을 포함하고, 사망자와 이민자를 표본에서 제외시킴.

- 2010년 2분기 이후 가계신용 분기보고서(Quarterly Report on Household Debt and Credit) 공표 중

$\triangleright$ 보고서 작성 시 표본 중 $0.1 \%(5 \%$ 표본 중 $2 \%)$ 를 추출 모집단으로 추정함. $\triangleright$ 대출 유형별(모기지, 학자금대출, 자동차대출, 신용카드)로 대출 및 연 체 상태, 모기지의 경우 지역별 현황 등의 내용을 공표하고 있음.

- 총대출 잔액·건수, 신규 및 종료된 대출 건수, 신규 대출 차입자 신용등급별 분포, 90일 이상 연체비율, 상환 상태별 전이율, 신규 압류 및 파산 건수 등

- 대표성 있는 표본 구성에 초점을 두었고, 패널 $\mathrm{DB}$ 를 통한 가계부채 총 량 추정치와 자금순환계정(Board of Governor's Flow of Funds)상 가계 부채 총량을 바로 비교할 수 있음.

$\triangleright$ 표본의 적정성 점검을 위해 인구센서스(American Community Survey)상 인구분포를 비교하여 표본 구성을 검토함.

- 모기지 주요 특성 정보 부족 및 다른 출처 $\mathrm{DB}$ 와 통합의 어려움, 이용 제 한 등 공적 가계부채 $\mathrm{DB}$ 로서 한계가 존재함.

$\triangleright$ 대출목적, 자가점유여부, 담보물 정보 부족, 소득, 차입자의 인구학적 특성 정보 부족 등의 문제가 존재함.

$\triangle \mathrm{FRB}$ 직원들에 한해 $\mathrm{FRB}$ 서버에 접속 이용이 가능하며, 새로운 변수 생성 및 원자료 업데이트는 Equifax와 계약관계가 있는 FRBNY에서 만 가능함.
3) $\mathrm{NMDB}$ (National Mortgage Database)

2012년부터 연방 주택금융청(FHFA)과 소비자금융보호국(CFPB)은 개별 모 기지대출 단위(loan-level)의 DB를 구축하는 중장기 프로젝트를 진행 중

$\triangleright$ 모기지 마이크로 $\mathrm{DB}$ 구축을 중심으로 연도별 모기지 공급자 조사, 모 기지 차입자 조사 3 개 부문으로 구성된 프로젝트임.

- NMDB(National Mortgage database)

- NSMO(National Survey of Mortgage Originations)

- ASM(American Survey of Mortgage Borrowers)

- 대출 발생 시점 정보에 기반하여 모기지 대출 DB 한계를 극복하고, 신 규 모기지와 주택시장 트렌드 이해에 도움이 되는 데이터를 구축하고자 함.

\1998년 1월부터 2012년까지 3대 신용정보회사에 1회 이상 기록이 있 는 차주의 모기지를 대상으로 가중치를 두어 $5 \%$ 표본을 추출, 분기별 로 신규 표본을 업데이트함.

$\triangleright$ 대출정보에 차입자와 담보물의 특성, 대출 후 상환 실적들을 지속적으 로 업데이트 할 예정임.

- 데이터 구축에 있어 다른 종류의 데이터베이스 데이터와 병합 기술적 해결, 월 별로 스냅샷 형태의 데이터 저장방식을 시간 트래킹이 가능한 구조로 변경함.

- 또한, 개인정보 식별이 불가능하도록 정보 처리를 하기 위해서 담보물 주소, 대출금액, 대출 시점 등 중요 정보처리의 이슈에 대해 논의 중임

\section{EU : ABS Loan-level Initiative}

\section{- ABS Loan-level Initiative}

$\triangleright$ 금융위기 이후 $\mathrm{ABS}$ 담보자산 풀(pool)에 대한 보다 미시적인 정보 수 집을 통하여 리스크 관리를 체계화하고, 시장 투명성을 증진시켜 자산 유동화 시장 활성화를 도모함.

$\triangleright$ 특히, $\mathrm{EU}$ 국가들의 데이터 표준화를 통한 정보 공유의 효율성을 높이 기 위하여 2009년 ECB는 ABS Loan-level initiative 프로젝트를 시 작함. 
- 10년 12월 RMBS(Residential MBS) 템플릿 구축을 시작으로, 11년 4 월 CMBS(Commercial MBS) SME(Small and Medium sized enterprise Securitisation) 템플릿을 구축하기 시작함.

\section{- RMBS 템플릿}

$\triangleright \mathrm{RMBS}$ 의 개별 대출 단위 정보 수집 템플릿은 10 년 ver 1.0 을 시작으 로 13년 6월 version 28까지 수정되었음.

- 2013년 10월 이후 신규 발행되는 RMBS의 경우 템플릿의 정보들은 최소 분기 별로, 각국 중앙은행에 제출하고, 수집된 정보는 European DataWarehouse 에 업데이트 됨.

$\triangleright$ 주요 항목은 차입자 정보, 이자율 정보, 담보물 및 추가 담보 정보, 상 환 실적 등으로 구분됨.

- 157 개의 항목이 있고, 그중 55 개 항목이 필수항목임.

\section{[그림 6-2] ECB RMBS 템플릿 형태}

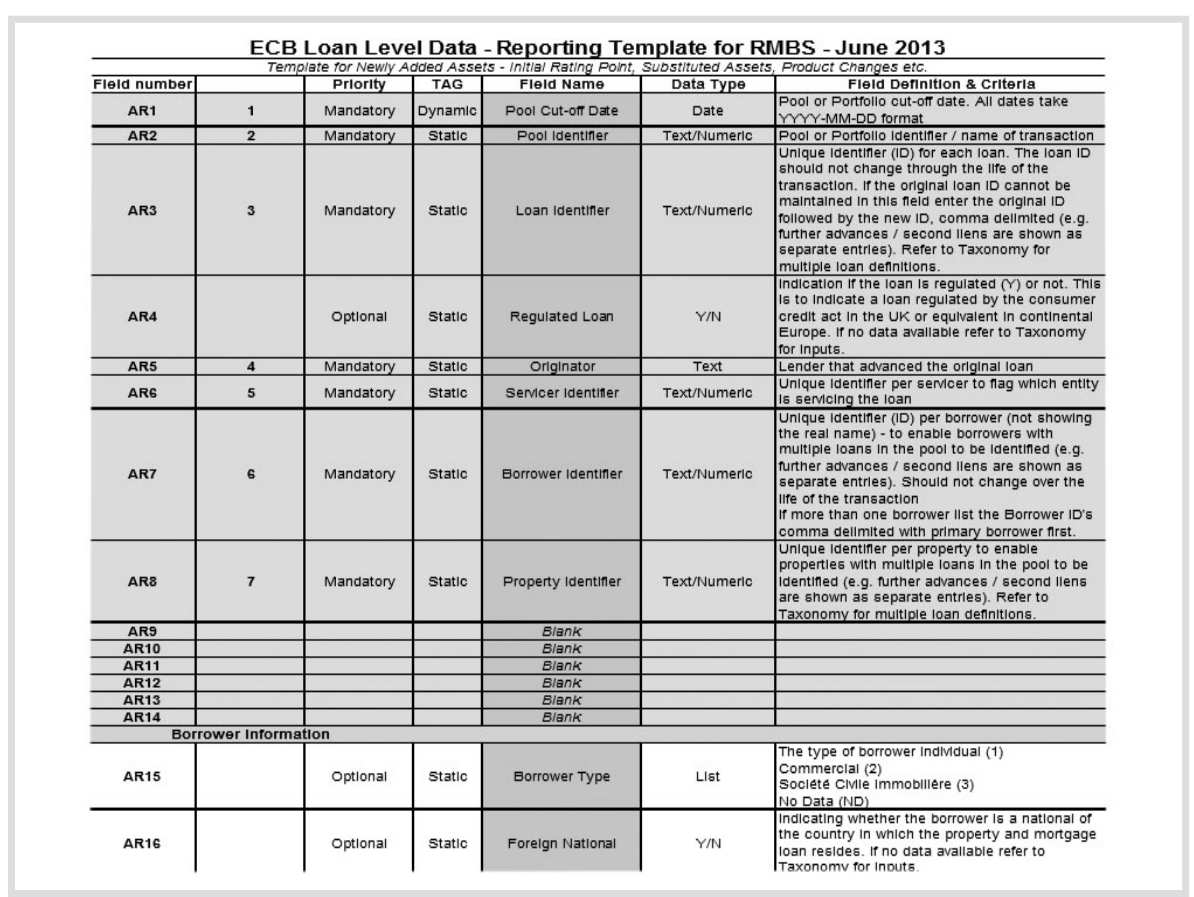

※ 자료 : $\mathrm{ECB}$

$\triangleright$ 신용평가사나 시장참여자들은 수집된 정보를 바탕으로 자산유동화증 권의 신용평가 및 현금흐름 예측의 정확성을 높이는데 기여할 것으로 기대됨.

\section{4. 시사점}

- 미국의 경우 활용 목적에 따라 차별성을 갖는 $\mathrm{DB}$ 들이 구축 및 보완되고 있고, EU의 경우 수집 데이터 표준화를 통하여 시장 투명성 증진을 도 모하고 있음.

$\triangleright$ 방대한 양의 정보를 효율적으로 수집 및 활용하기 위해서는 $\mathrm{DB}$ 구축 목적을 명확하게 설정하고, 이에 기반하여 데이터 수집 범위, 항목 등 을 확장해야 함.

$\triangleright$ 또한 지속적인 업데이트를 위해서 금융기관들의 데이터 표준화 과정이 중요함.

- 한국의 경우도 2018년 가계금융복지조사를 개편하고, 한국은행이 '14년 마이크로 가계부채 $\mathrm{DB}$ 를 구축하는 등 가계금융 마이크로 $\mathrm{DB}$ 를 보완중 에 있음.

$\triangleright$ 가계금융복지조사의 경우 2010년 이후 2 만 가구 대상으로 실시된 면 접조사를 ' 18 년까지 가계부채 부문 표본가구 확충 및 행정자료와 연계 할 예정임.

$\triangleright$ 한국은행의 경우 $\mathrm{FRBNY}$ 의 CCP를 벤치마크하여 2014년 DB를 구축 함.

- 2016년 이후 금융안정보고서 등에 $\mathrm{DB}$ 활용 분석이 포함되기 시작하였지만, 아직 정례화된 동향보고 양식은 없음. 또한, 구축 DB 데이터 풀(pool) 형성 및 유지 방식에 대한 정보가 부족함.

- 금융 데이터의 특수성을 고려할 때, 중장기적인 로드맵 하에 단계적으 로 마이크로 $\mathrm{DB}$ 를 구축하여야 실제로 유용하게 활용 가능할 것임.

$\triangleright$ 개인정보보호 문제 등 금융정보 수집의 특수성, 소득 및 담보물 특성 정보 등의 다른 통계와의 병합 가능성, 대표성 있는 표본 구축 등 단기 에 해결하기 어려운 이슈들이 존재함.

$\triangleright$ 가계금융 시장을 포괄하여 모니터링 할 수 있는 마이크로 $\mathrm{DB}$ 구축을 위해서 각각의 이슈에 대한 충분한 연구와 검토가 필요함. 